\title{
A NECESSIDADE DE APLICAÇÃO DO EXAME OCUPACIONAL ODONTOLÓGICO COMO MEIO DE GARANTIR A PROTEÇÃO À SAÚDE DO TRABALHADOR
}

\author{
Andreia Regina Boff Lemos ${ }^{1}$ \\ Walter Gustavo da Silva Lemos²
}

\section{RESUMO}

A Odontologia do Trabalho contribui para a manutenção da saúde e da qualidade de vida do indivíduo no desempenho do seu trabalho, atuando de forma multidisciplinar, agregando não só conhecimentos específicos da odontologia, mas abrangendo outras áreas, e estudando as relações entre as implicações que os locais de trabalho determinam sobre a saúde do sistema estomatognático do trabalhador. Este trabalho tem o intuito de demonstrar a real necessidade da presença do cirurgião dentista dentro do ambiente laboral, fomentando a prática do novo projeto de lei que obriga a presença do cirurgião dentista nos exames admissionais, periódicos e demissionais do trabalhador.

Palavras-chave: Odontologia do Trabalho; Exame Médico Periódico; Projeto de Lei.

\section{THE NEED FOR THE APPLICATION OF THE OCCUPATIONAL DENTAL EXAMINATION AS A MEANS TO GUARANTEE THE PROTECTION OF THE WORKER'S HEALTH}

\begin{abstract}
Dentistry Labour its main objective to contribute to maintaining the health and quality of life of the individual in the performance of their work, working in a multidisciplinary way, adding not only specific knowledge of dentistry, but covering other areas, and studying the relationship between the implications of workplaces determine on the health of the worker stomatognathic system. This paper aims to demonstrate the real need of the dentist presence in the workplace, encouraging the practice of new bill that requires the presence of the dentist in the admission examinations, periodic and dismissal of the worker.
\end{abstract}

1Mestranda em Ciências da Saúde e Tecnologia pela, Faculdades Integradas de Goiás - FIG, Goiás, (Brasil)..

E-mail: andreiarblemos@ hotmail.com

2Doutorando em Direito pela, Universidade Estácio De Sá - UNESA/RJ, Rio de Janeiro, (Brasil). Advogado, Professor da FCR - Faculdade Católica de Rondônia e da FARO - Faculdade de Rondônia.

E-mail:wgustavolemos@gmail.com 
Keywords: Dentistry; dental work; periodic medical examination; bill.

\section{INTRODUÇÃO}

O campo de trabalho cada dia é mais concorrido, bem como se torna mais difícil a busca por profissionais tecnicamente habilitados para o exercício dos trabalhos buscados pelo mercado. Neste contexto, é vital que o trabalhador tenha as melhores condições de saúde possíveis a fim de desenvolver o seu labor diário, sem que apresenta qualquer doença ou alterações de saúde que impeçam o total desenvolvimento de suas habilidades.

Mas é sabido que muitas vezes este trabalhador acaba não podendo cumprir o seu trabalho constantemente, ante a existência de uma série de doenças que acaba desenvolvendo diariamente, advindo muitas delas do próprio ambiente de trabalho.

Assim, há que se promover o monitoramento do trabalhador durante o cumprimento do seu período de trabalho, bem como deve o ambiente de trabalho ser constantemente controlado para impedir a proliferação de meios que possam levar ao aparecimento de doenças ocupacionais, que são responsáveis pela maior parte do absenteísmo.

Como a falta do trabalho acaba por impactar diretamente no processo de produção, é necessário que mecanismos sejam promovidos para combater tais doenças ocupacionais e as causas do absenteísmo.

No presente trabalho, torna-se importante o estudo da questão relacionada à aplicabilidade do exame ocupacional odontológico nas mesmas condições do exame médico admissional, periódico e demissional obrigatórios, vez que uma grande parte das doenças ou problemas de saúde que causam o absenteísmo são de origem odontológica.

Se grande parte das faltas ao trabalho ocorrem por motivação odontológica, será que a periodicidade e imposição descrita no artigo 168 da Consolidação das Leis do Trabalho (CLT) para o exame médico obrigatório pode ser aplicada ao exame ocupacional odontológico?

A presença do médico e o enfermeiro é importante para a promoção da saúde do trabalhador, sendo que a norma (CLT) acaba por descrever a obrigatoriedade da atuação de tais profissionais como promotores da saúde integral dos trabalhadores. Estes atuam promovendo a fiscalização das condições de trabalho, o conhecimento dos danos causados em função da utilização de certas substâncias químicas e tóxicas derivadas, sendo ponderosa a presença destes profissionais habilitados em promover, preservar e recuperar a saúde dos 
trabalhadores e a presença de equipamentos de proteção coletiva e individual interfere sobremaneira na qualidade geral e oral dos trabalhadores. O Cirurgião Dentista também tem um papel fundamental no diagnóstico precoce de doenças ocupacionais com envolvimento sistêmico, porém com manifestações bucais, agindo como agente promotor de saúde e preservando a saúde oral como fator significante na manutenção da saúde geral e a integridade do trabalhador. Se o odontólogo é tão importante para a saúde do trabalhador, necessária é a aposição na norma (CLT) da obrigatoriedade da presença deste profissional na realização de exames laborais da mesma forma como exigido do exame médico ocupacional.

Desta forma, imperiosa é a necessidade de se descrever a importância do Odontólogo na promoção de exames admissional, periódicos e demissionais dentro do contexto de saúde geral do trabalhador.

Mas para que tal situação seja estudada, impõe-se a descrição de que a periodicidade descrita no artigo 168 da CLT deve ser aplicada ao exame ocupacional odontológico, a fim de que se entenda a importância do texto aposto na norma e a extensão desta à odontologia como meio de combate a uma grande causa das ausências no trabalho, que são as doenças odontológicas.

Insta lembrar que o estudo acima não causará o efeito necessário, se não for prosseguido do estudo do caput do Artigo 168 da CLT na forma hoje descrita, bem como da análise do Projeto de Lei n 422/2007, em trâmite na Câmara dos Deputados, que visa alterar o Artigo 168 da CLT, descrevendo a necessidade da ocorrência de exame ocupacional odontológico dentro das rotinas do exame ocupacional "para apuração da capacidade ou aptidão física e mental do empregado para a função que deva exercer".

Não se pode esquecer que para a demonstração destes objetivos, há que se confrontar às razões que levam ao estabelecimento das regras aplicadas ao exame médico ocupacional obrigatório, para a descrição desta mesma obrigatoriedade para a área odontológica.

O presente artigo tem como finalidade uma revisão bibliográfica exploratória, em que o pesquisador objetiva familiarizar-se com o assunto por meio de sua própria intuição apoiada em pesquisa bibliográfica que descrevam problemas semelhantes ou análise de exemplos análogos que possam estimular a compreensão da ideia (GIL, 2008).

A pesquisa bibliográfica exploratória será de natureza qualitativa, pois ser refere a uma pesquisa de coleta de dados e informações disponíveis na literatura, não requerendo, portanto, o uso de métodos e técnicas quantitativos.

A finalidade da pesquisa é estabelecer uma conexão entre o saber teórico da odontologia ocupacional e sua prática, por meio da análise do Projeto de Lei $n^{\circ}$ 422/2007 e 
dos documentos que lhe fazem parte, que serão utilizados como fonte de dados para a pesquisa.

Assim, o presente artigo se dividirá primeiramente numa abordagem de como se encontra questão do exame ocupacional na legislação em vigor, para passar a abordar a questão sobre a necessidade da presença do odontólogo na relação empregado/empregador por via do exame ocupacional, para, por fim, terminar descrevendo o estudo do Projeto de Lei $n^{\circ} 422 / 2007$.

\section{O EXAME OCUPACIONAL NA LEGISLAÇÃO EM VIGOR}

O presente artigo objetiva promover a análise das questões relacionadas ao exame ocupacional descrito na norma descrever que a periodicidade descrita no Artigo 168 da CLT deve ser aplicada ao exame ocupacional odontológico, de forma a que os odontólogos sejam inseridos definitivamente dentro do sistema de saúde laboral.

Tem que se fazer um breve retorno à Revolução Industrial para que se possa fazer o registro que aquele evento acaba por promover a mudança do regime de trabalho adotado, não mais por via do serviçalismo e sim como meio de contraprestação de um salário recebido pelo empregado do seu empregador.

Ocorre que tal regime acabou por impor a este novo trabalhador situações de trabalho em ambientes fechados, insalubres, por horas a fio, sem o devido descanso e alimentação necessária. Há que se somar a isso as condições de saneamento e de miséria do trabalhador, que fazem surgir outro grande problema: adoecimento dos trabalhadores que passaram a sofrer acidentes e desenvolver doenças nas áreas fabris.

A grande parte desta mão de obra era composta de mulheres e crianças que sofriam a agressão de diversos agentes, oriundos do processo e/ou ambiente de trabalho, quando na verdade deveria ter condições especiais, mas a exploração desta massa de trabalho acabou com o tempo importando perdas econômicas para os empregadores.

A partir destas situações de perdas, surge a necessidade da intervenção estatal dentro dos estabelecimentos fabris para permitir a melhora das condições de saúde do trabalhador, sendo que em meados do século XIX surgem as primeiras leis de saúde pública abordando as questões da falta de condição no ambiente laboral, descrevendo a necessidade de que os médicos passam a atuar junto às fábricas (MENDES, 1980).

Tem-se ai o início da Medicina do Trabalho, como um meio de descrever conhecimentos a soma da medicina científica à Medicina Social, onde aspectos como habitação, saneamento, trabalho e outros entram como cofatores determinantes na gênese do 
processo de doenças, mas tais praticas descritas na norma como meio de controle da força de trabalho através do aumento da produtividade e regulação do absenteísmo (MENDES \& DIAS, 1991), acabam por não se implementar a contento.

Concomitantemente com isso, o mundo passa a conviver com os ideais marxistas, o socialismo e comunismo, como meio de contraponto ao ideário capitalista de exploração da força de trabalho, sendo que estes ideais acabam levando a uma busca por melhores condições de trabalho e a descrição de direitos advindos desta relação (HOBSBAWM, 1995).

As relações de trabalho continuavam em grande desvantagem para o trabalhador, sendo que no início do século XX, com o fito de equilibrar a relação capital-trabalho, emergem os movimentos sindicais como meios de luta pelo controle social da força de trabalho, passando a promover pressões aos governos estabelecidos para a normatização dos direitos do trabalhador e a descrição de um sistema de defesa da saúde laboral.

A adoção de novas tecnologias ao processo de trabalho acabaram por aumentar os riscos à saúde do trabalhador, pelo crescimento dos acidentes de trabalho e doenças profissionais, sendo que neste momento a Medicina do Trabalho ainda engatinhava, sendo pensada somente sobre a ótica da medicina do corpo, individual e biológica, estruturada sobre uma atuação do trabalhador, com uma abordagem clínico-terapêutica ( TAMBELLINI, 1993).

Neste contexto é que surge a Organização Internacional do Trabalho (OIT), em 1919, como uma organização internacional que objetivava a luta pela regulamentação dos direitos do trabalhador, sendo que dentre eles estavam os direitos inerentes às boas condições de saúde. Esta organização internacional foi importante para a busca do processo de normatização dos direitos laborais e do controle das doenças profissionais, sendo que até hoje luta por tais condições.

Por pressões internas, promovidas pelas associações e sindicatos e pelas greves de trabalhadores, bem como por meio das pressões promovidas pela OIT, o governo brasileiro passou a normatizar as relações laborais a partir da Consolidação das Leis do Trabalho (CLT), devidamente/ assinado pelo Presidente Getúlio Vargas em 1 de maio de 1943, por via do Decreto-Lei $\mathrm{n}^{\mathrm{o}} 5.452 / 43$, com o objetivo de unificar as normas trabalhistas já existentes e descrever novas obrigações nesta regulamentação das relações individuais e coletivas do trabalho.

No art. 162 da CLT acaba por descrever em seu caput a obrigação das empresas, estabelecerem uma política de segurança e medicina no trabalho, que acaba por se implementar baseado na interdisciplinaridade e na multiprofissionalidade da proteção da saúde do trabalhador, por meio da "organização de equipes progressivamente 
multiprofissionais, e a ênfase na higiene industrial, refletindo a origem histórica dos serviços médicos e o lugar de destaque da indústria nos países industrializados." (MENDES \& DIAS, 1991)

Assim, a norma inicia a descrição da importância do estabelecimento pelas empresas de normas de proteção ao trabalhador, tanto na questão de sua segurança, quanto como meio de combate às doenças profissionais e do trabalho. Embora este artigo não constava com a redação hoje descrita, este pensamento já imperava naquela Consolidação.

Já no art. 168 da mesma CLT, vai descrever a necessidade de que o trabalhador seja acompanhado durante o seu labor por meio de exames médicos, realizados na sua admissão e demissão, bem como periodicamente de acordo com as normas específicas a cada uma das profissionais, sendo estas normativas descritas pelo Ministério do Trabalho.

Este exame é um processo de avaliação médica, com o auxílio de outros profissionais da saúde, por meio da anamnese do paciente com o objetivo de tentar identificar moléstias, sinais e sintomas causados ou não pelo exercício das atividades relacionadas ao trabalho, onde se deve realizar um exame admissional, como uma avaliação para que se descreva se o trabalhador detém a saúde necessária para a realização da função a ser exercida.

Já o exame demissional é o exame que tem a finalidade de avaliar as condições de saúde do empregado para que possa ser desligado em definitivo de suas funções na empresa, por meio de uma rescisão do contrato de trabalho.

Por último temos que, o exame periódico é aquela avaliação que objetiva identificar doenças profissionais e do trabalho durante o cumprimento do contrato de trabalho, de acordo com as periodicidades aplicáveis aos casos específicos, tudo conforme o Programa de Controle Médico e de Saúde Ocupacional (PCMSO).

\section{A IMPORTÂNCIA DA PRESENÇA DO ODONTÓLOGO NA RELAÇÃO EMPREGATÍCIA POR VIA DO EXAME OCUPACIONAL}

$\mathrm{O}$ atual perfil da odontologia preocupa-se com a prevenção trazendo uma concepção de saúde bucal não somente de dentes preservados, mas sim de qualidade de vida. Desta forma, a atenção à saúde bucal deve ser direcionada a todas as faixas etárias e populações específicas (CUNHA, 2005).

GUIMARÃES ROCHA et al. (1979) definem a Odontologia do Trabalho como "a parte da Odontologia que trata de promover, preservar e reparar a saúde do trabalhador, consequente dos agravos, afecções ou doenças advindas do exercício profissional e que se 
manifestam na boca", de forma que esta é a parte da odontologia que cuida do estudo da relação entre a saúde bucal e a sua inter-relação com o trabalho.

Diferindo das demais especialidades por ter a sua ação diretamente dirigida e voltada para a prevenção de todos os agravos à saúde bucal do trabalhador que decorram de suas atividades laborais, objetivando a prevenção de doenças consequentes da atuação profissional e dos acidentes do trabalho.

Entende-se por doença profissional toda aquela doença produzida ou desencadeada pelo exercício do trabalho, peculiar à determinada atividade; e por doença do trabalho toda aquela doença adquirida ou desencadeada em função de condições especiais em que o trabalho é realizado, desde que com ele se relacione diretamente (MAZZILLI, 2003).

Para o médico do trabalho é no exame periódico que se encontra uma ferramenta importante para a avaliação da saúde do trabalhador, onde pode-se avaliar as condições de trabalho, objetivando sempre a prevenção. Se no programa de controle médico em saúde ocupacional (PCMSO), realizado pelo médico do trabalho, é possível a identificação das condições de riscos nocivos em que o trabalhador é submetido e há a propositura de medidas de proteção, seja com o uso de Equipamentos de Proteção Individuais -EPI’s - ou mesmo através de barreiras que impeçam o agente nocivo de entrar em contato com o trabalhador, é através do Exame Periódico que se controla a sua saúde "física e psicológica", onde se podem analisar as alterações dos vários parâmetros utilizados na avaliação, utilizando-se para tanto uma anamnese, exame clínico e exames laboratoriais de rotina e específicos, orientados para cada risco a que está exposto o trabalhador (OLIVAL ET AL 2008).

O Conselho Federal de Odontologia, após perceber a importância da saúde bucal no trabalho, a partir de 1999, inseriu a odontologia no programa de controle médico em saúde ocupacional (PCMSO) da secretaria de Segurança e Saúde do trabalho, do Ministério do Trabalho, tendo como finalidade o estudo, a compreensão e a solução dos diferentes problemas que atingem os trabalhadores.

Assim, a Odontologia do trabalho é uma especialidade que tem como objetivo a busca permanente da compatibilidade entre a atividade laboral e profissional e a preservação da saúde bucal do trabalhador (Resolução CFO 22/2001 de 27/12/2001, Art. 30) sendo função do dentista do trabalho reconhecer e prevenir riscos ambientais causadores de manifestações orais de doenças profissionais, e a correção de lesões orais e condições afins devidas à exposição a fatores profissionais (MEDEIROS, 2011).

A função da odontologia do trabalho foge da odontologia assistencial, intervencionista, preventiva/curativa, ela se utiliza de todos os conceitos estudados dentro da 
prática clínica, e desenvolve suas funções se fundamentando na promoção e preservação da saúde bucal do trabalhador, pois em algumas doenças sistêmicas há o aparecimento de manifestações bucais (SANTOS, 2007). No aspecto da promoção da saúde o profissional tem a função da conscientização do trabalhador em relação à saúde de um modo geral, transformando-os em multiplicadores dos conhecimentos adquiridos (HIROISHI, W.K. et al 2011; PIZZATTO et al, 2006), levando tais conhecimentos para a família e amigos.

Como benefícios para o trabalhador da inclusão do cirurgião-dentista, especialista em odontologia do trabalho dentro da empresa, tem-se a decorrente diminuição dos índices de cárie e doença periodontal, redução dos problemas da dor, isso devido aos exames periódicos e orientações para a promoção e manutenção da saúde bucal. O trabalhador sadio reduz os índices de absenteísmo, gera menores custos à empresa, produz mais e melhor, evita afastamentos desnecessários, reduz taxas de acidentes de trabalho, evita custos com a contratação e treinamento de novos funcionários, havendo melhoria da relação empregadorempregado e cumprimento da lei de responsabilidade social a que a empresa necessita cumprir. Para o país, o benefício se dará pela diminuição do número de acidentes de trabalho que sobrecarregam o sistema previdenciário, reduzindo os gastos e gerando mais riquezas (HIROISHI, 2011).

Os exames clínicos bucais constituem formas de monitoramento da saúde do trabalhador, pois indicam dados concretos da condição de saúde/doença dos trabalhadores de cada empresa, para que esta possa planejar a sua atuação em saúde da forma mais conveniente e adequada de acordo com a situação de saúde presente. Além disso, caracterizam-se em relação ao tempo de sua execução podendo ser chamados de iniciais, periódicos, de mudança de função e demissionais (HIROISHI, 2011).

Dentro das doenças que o trabalhador pode adquirir no seu ambiente de trabalho, algumas produzem manifestações bucais, que podem advir de diversas causas, podendo decorrer de (HIROISHI, ABOT e SÁ, 2011):

1 - Doenças causadas por agentes físicos: são aquelas doenças devidas à ação de agentes físicos, tais como a pressão atmosférica; temperatura; umidade do ar; fontes de energia radiante; ação de substâncias ionizantes; 2 - Doenças causadas por agentes mecânicos: são aquelas doenças devidas à ação de agentes tais como vibrações, repetição frequente de movimentos, posições viciosas de trabalho, impactos, entre outras;

3 - Doenças causadas por agentes químicos: causadas por agentes químicos presentes nas indústrias;

4 - Doenças causadas por agentes biológicos: são aquelas doenças causadas pelo contato com agentes etiológicos de doenças infectocontagiosas ou parasitárias, devido às necessidades do trabalho. 
A realização de exames periódicos permitem um diagnóstico precoce de alterações da saúde bucal e/ou sistêmica cuja causa pode ser determinada ou agravada pelo trabalho; permitem a investigação e adoção de medidas de controle e/ou eliminação de riscos para a saúde; a revisão, avaliação e modificação dos programas de saúde e o sistema assistencial; Subsidiar o planejamento do atendimento das necessidades acumuladas no período; Correção de defeitos pequenos e detecção de doenças em seu estágio incipiente; Encorajamento do tratamento, quando da suspeita de problemas sérios, e recomendar o tratamento, quando negligenciado pelo trabalhador (SILVA, 2010).

Um grande problema para a relação trabalhador empregador é o absenteísmo odontológico no qual se entende ser a ausência do empregado ao trabalho, motivada pela má condição de saúde, seja geral ou oral. É caracterizado pela perda temporária da capacidade de trabalho, em sua jornada laboral, ou ainda, sua presença insatisfatória ou precária no trabalho. (MAZZILLI, 2003). Dentre os problemas que motivam o absenteísmo, a dor de dente ocupa a terceira posição ficando atrás somente da dor de estômago e de cabeça (PIZZATTO, 2006; SANTOS, 2007).

O crescimento real da Odontologia do trabalho no país está diretamente ligado a uma legislação que obrigue as empresas a adotarem o serviço odontológico ocupacional, assim como existe hoje com a Medicina do Trabalho. Por conta disso, foi encaminhado o Projeto de Lei (PL) no 3.520, de 11 de maio de 2004, à Câmara dos Deputados, alternando os artigos 162, Seção III, e o artigo 168, Seção V; do capítulo V do Título II da Consolidação das Leis do Trabalho (CLT), relativo à Segurança e Medicina do Trabalho e dá outras providências. Este projeto não teve o seu andamento promovido, sendo reapresentado pelo Projeto de Lei $\mathrm{n}^{\mathrm{o}}$ 422/2007, de 14/03/2007, de autoria do Deputado Flaviano Melo (PMDB/AC).

NOGUEIRA (1972) classificou as doenças ocupacionais da cavidade bucal e estruturas adjacentes em dois grupos, sendo o primeiro grupo de doenças devidas às ações diretas do agente causal sobre as estruturas da boca, e o segundo grupo o de doenças bucais surgidas a partir de uma doença sistêmica (BURKET, 1952; NOGUEIRA, 1972).

Com base nisso fica demonstrada a necessidade da presença do odontólogo na avaliação da saúde do trabalhador, da mesma forma que a lei descreve como obrigatória a atuação do médico nos exames ocupacionais.

\section{DOS BENEFÍCIOS DA ODONTOLOGIA DO TRABALHO PARA O TRABALHADOR}


Este ramo da Odontologia que tem por objetivo a melhoria da saúde oral dos trabalhadores, acaba por trazer uma série de benefícios laborais que acabam por influenciar positivamente a produtividade no trabalho. Assim, o deve odontólogo realizar as suas atividades na busca pela preservação da saúde bucal do trabalhador em sua atividade ocupacional, na implementação das políticas públicas de Segurança e Saúde do Trabalhador, com base nas Normas Regulamentadoras (NR’s) expedidas pelo Ministério do Trabalho e Emprego.

Sob tal perspectiva, o odontólogo estabelece uma busca permanente da compatibilidade entre a atividade laboral e a preservação da saúde bucal dos trabalhadores, com a promoção de atividades preventivas, de forma a desenvolver atividades ajustadas a cada realidade ocupacional, bem como diagnosticando possíveis manifestações de doenças orais ocupacionais, tudo como forma de promover a manutenção da saúde oral dos trabalhadores no ambiente de trabalho.

Para isso, o odontólogo se utiliza dos exames odontológicos ocupacionais, sendo estes os exames admissionais, periódicos, mudanças de função, retorno às funções laborais e demissionais, como meio de promover a prevenção de situações de importem riscos à saúde ou causem doenças ao trabalhador, sendo uma ferramenta de gestão da saúde bucal no ambiente empresarial.

O labor diuturno do trabalhador pode trazer danos à sua saúde, o que acaba por importar na geração de prejuízos diretos e indiretos ao empregador, que podem ser minimizados com os exames ocupacionais realizados pelo odontólogo do trabalho, diminuindo as situações de absenteísmo por causa odontológica, a proteção e combate aos acidentes de trabalho nos empregados e das doenças profissionais que atinjam a cavidade bucal.

Assim, o cirurgião-dentista interagindo dentro do ambiente de trabalho com o trabalhador acaba por atuar no sentido de manter o estado de saúde e o bem-estar do trabalhador, dentro do ambiente de trabalho, ajudando no processo de conscientização do trabalhador sobre a importância da saúde bucal e sua influência na sua saúde geral, de forma a possibilitar a sua inclusão em programas sociais ou institucionais de atenção a saúde bucal como forma de garantir a plenitude da sua saúde oral.(SILVA e MEDEIROS, 2013)

Ainda, esta atuação do profissional da saúde bucal dentro da atividade de saúde laboral acaba por importar na difusão da necessidade de prevenção e promoção da cura das doenças que acometem os dentes e a cavidade oral, bem como a devida atividade orientativa ao trabalhador sobre a importância do uso de equipamentos de proteção individual para 
preservação da própria saúde, principalmente naqueles ligados à proteção da região bucal e das regiões próximas.

Este tipo de cuidado da empresa com o seu trabalhador acaba por valorizá-lo, melhorando a sua saúde e autoestima, o que importa numa melhor capacidade de produção e cumprimento de suas tarefas laborais (MORETTI, 2005), o que mostra a importância do desenvolvimento de um programa em Odontologia Ocupacional, nas mais diversas empresas já que os riscos à saúde bucal do trabalhador pode ocorrer dentro de processos de produção industriais ou até em serviços administrativos, já que em todos há uma exposição a agentes químicos, físicos, biológicos ou outros podem interferir em sua saúde bucal.(ARAUJO e GONINI JUNIOR, 1999)

\section{UMA ABORDAGEM DO PROJETO-LEI No 422/2007 EM CURSO DA CÂMARA DOS DEPUTADOS:}

O Projeto-lei, cuja autoria é do Deputado Federal Vanderlei Assis de Souza (PP/SP), obriga as empresas a manterem serviço de assistência odontológica aos empregados, além de inserir o especialista em odontologia do trabalho no quadro de profissionais do SESMT. O projeto foi reapresentado em 2007 pelo Deputado Flaviano Melo (PMDB/AC), através do PL $n^{\circ}$ 422/2007, que ainda se encontra em trâmite no Congresso Nacional.

O objetivo do presente projeto é a inclusão do profissional de Odontologia no ambiente de trabalho, para que a partir de tais atuações possa melhorar a autoestima do trabalhador, diminuindo sua falta ao trabalho e aumentando a produtividade do empregador.

O projeto propõe a realização de um grande avanço tanto na vida do trabalhador e das empresas, a inserção do Odontólogo no Programa de saúde Ocupacional, de modo a que se minore as faltas ao trabalho por causa de problemas odontológico, bem como atuem em situações laborais especiais como os grandes acidentes, tragédias e situações endêmicas setoriais, para diminuir os danos ao trabalho e harmonizar o ambiente de trabalho.

O projeto descreve a importância da modificação da CLT nos seus artigos 162 e 168, sendo que no primeiro a mudança legislativa se daria pela inserção da figura do profissional da Odontologia do Trabalho no programa de saúde ocupacional das empresas, que deverão promover a prestação do serviço odontológico como meio de preservar a saúde bucal dos trabalhadores.

Já o art. 168 do CLT acabaria por ser modificado para inserir dentro das obrigações da empresa a realização exames ocupacionais nas áreas médicas e odontológicas, sendo tal 
inserção da odontologia nos exames laborais se dariam nas mesmas formas e condições em que os exames médicos.

Assim, os exames odontológicos ocorreriam na admissão e demissão dos trabalhadores, bem como na periodicidade que a norma regulamentar acabasse por entender para as respectivas situações específicas.

Nas justificativas da apresentação do projeto legislativo para a mudança da CLT, descreve-se que o objetivo é de "atenção à saúde bucal é parte integrante das ações de saúde em geral, não devendo ser negligenciada, dada a importância dos transtornos bucais na gênese de acidentes de trabalho e do absenteísmo nas empresas."

Mas não há como se falar em uma saúde integral do trabalhador sem que o odontólogo passe a atuar nas ações ocupacionais de saúde bucal, a serem descritas nos Programas de Saúde Ocupacional por odontólogos que sejam "devidamente capacitados para lidar com a especificidade da relação saúde bucal e trabalho", como justificado no Projeto-lei.

SANTOS (2007) vai salientar que o bem-estar e a saúde do trabalhador devem ser bem observados por empresários cujo objetivo é a preservação, conservação de um completo bem-estar, físico, mental e social de seu trabalhador, pois o máximo de sua capacidade produtiva beneficiaria a própria empresa que utilizasse tal tipo de programa de saúde bucal para o trabalhador.

Já COSTA (2008, pág. 7) vê “a integração da Odontologia do Trabalho aos Sistemas de Gestão da Saúde e Segurança no Trabalho um favorecimento ao país, com a diminuição da demanda e da procura pelos serviços odontológicos das unidades básicas de saúde, o que permite que outras categorias da população sejam melhores assistidas."

Assim, possível é de se ver, como descreve COSTA (2008, pág. 19), que a inserção da Odontologia nos "Sistemas de Gestão da Saúde e Segurança no Trabalho das organizações pretende assumir sua responsabilidade social relacionada à saúde dos trabalhadores, bem como contribui com o aumento da estabilidade do setor industrial e de serviços, da produtividade e segurança no trabalho", importa na busca pela plenitude da saúde do trabalhador.

Perceptível, portanto, que o Projeto-lei acima tratado é de grande importância para a saúde do trabalhador, que teria condições de trato dos seus problemas odontológicos, mas também pela intervenção do Odontólogo nas empresas como meio de melhora das condições laborais que possam afetar a saúde bucal do trabalhador e na formação desta como um agente propagador da importância da saúde bucal para seus familiares e amigos. 
Mas claro que o atual Projeto-lei em curso no Congresso Brasileiro precisa prosseguir, continuando a sua marcha para a sua aprovação e modificação dos textos legais da CLT, a fim de trazer benefícios sociais importantes para o trabalhador, sua família, ao empregador e à economia como um todo, posto que esta atuação odontológica propiciaria uma melhora da saúde bucal, reduzindo com isso o absenteísmo odontológico, a partir de ações de promoção de saúdes voltadas às distintas especificidades dos trabalhadores (HIROISHI, ABOT e SÁ, 2011).

\section{DO ATENDIMENTO ÀS NORMAS CONSTITUCIONAIS SOBRE A SAÚDE DO TRABALHADOR}

A Constituição Federal de 1988 descreveu a descrição da saúde do trabalhador como um direito social de importante resguardo, sendo necessário os entes públicos descreverem políticas públicas que visem o atendimento das melhores condições para o exercício do trabalho, bem como a necessidade de descrição de normas e regulamentações que objetem a redução dos riscos à saúde advindas do exercício da atividade laboral.

Podemos ver este conteúdo normativo na leitura do art. $6^{\circ}$ da Carta Magna, que tratou sobre o os direitos sociais, onde fica clara a preocupação do Estado com a saúde de sua sociedade, sendo que o tema de direito à saúde do trabalhador volta a baila no art. $7^{\circ}$ do mesmo texto, ao dizer que:

Art. $7^{\circ}$. São direitos dos trabalhadores urbanos e rurais além de outros que visem à melhoria de sua condição social:

(..)

XXII - redução dos riscos inerentes ao trabalho, por meio de normas de saúde, higiene e segurança.

XXVIII - seguro contra acidentes de trabalho, a cargo do empregador, sem excluir a indenização a que está obrigado, quando incorrer em dolo ou culpa.

Assim, é de se ver que o legislador constituinte destacou a importância da defesa dos direitos à saúde do trabalhador, importando em necessidade de redução de riscos à saúde advindos do exercício do trabalho. É de se notar que a norma constitucional não encontrou limitações, bem como não restringiu as questões de saúde somente ao campo da atuação médica, o que é de se perceber que a atuação do odontólogo dentro da saúde laboral se enquadra ao texto constitucional.

A norma constitucional ainda descreve sobre o tema da saúde do trabalhador, aportando o seu enredo sobre a necessidade da promoção de políticas públicas de atendimento à saúde do trabalhador, como se lê no Art. 200 deste texto, que trata sobre esta competência 
quando descreve que "ao Sistema Único de Saúde (SUS), compete (...) executar as ações de vigilância sanitária e epidemiológica, bem como as de saúde do trabalhador."

Assim, é perceptível que o constituinte descreveu como competência do seu próprio programa constitucional voltado à saúde, a preocupação com as ações de saúde geral e mais especificamente com a saúde do trabalhador, de forma que este estado do trabalhador foi alçado a uma importância constitucional que anteriormente não possuía, de forma que é uma responsabilidade de Estado da promoção da saúde geral do trabalhador, açambarcando, portanto, todas as esferas de políticas de saúde. Esta preocupação do constituinte com a questão da saúde do trabalhador é um apontamento como um direito fundamental, como se vê na afirmação de OLIVEIRA SILVA onde

Se a saúde do trabalhador é algo a ele inerente, imanente, em respeito à sua dignidade essencial e até mesmo para uma boa prestação de serviços ao empregador, trata-se de um direito natural, no sentido de intrínseco à conformação de sua personalidade e de seu desenvolvimento enquanto pessoa. É um direito imprescindível para o ser humano. De tal forma que assim se insere no continente maior dos direitos humanos, como conteúdo destes, vale dizer, como um dos valores fundamentais do sistema jurídico, sem o qual a dignidade da pessoa humana estará seriamente ameaçada. (2007, p. 119-120)

Assim, essas normas constitucionais de proteção são de grande relevância, embora não sejam portadoras de extrema efetividade, já que continuamos afundados num grande número de trabalhadores com a perda da saúde, pelos mais distintos motivos, desde doenças profissionais até a ocorrência de acidentes de trabalho, o que é causa de grande preocupação. É notável que o Brasil possui um sistema importante de proteção à saúde e à vida do trabalhador, necessitando deste cumprir com totalidade a sua finalidade.

A Consolidação das Leis do Trabalho (CLT) é outra norma que versa sobre esta temática, complementando o texto constitucional, ao trazer normas e regras que protegem o trabalho e o trabalhador, resguardando a sua saúde. Nesta norma fica consignada a necessidade da atuação do médico como importante sujeito na promoção da saúde do trabalhador, devendo realizar os exames determinado no art. 168 daquela norma como meio de garantir a certeza da saúde e proteção do trabalhador no exercício do seu labor.

Ocorre que o texto constitucional foi mais amplo na dicção da proteção da saúde do trabalhador, não se tratando este cuidado somente aos usos descritos nas incursões e exames médicos, mas a todos os meios de profissionais inerentes ao conhecimento da área da saúde, sendo necessária a atuação do odontólogo do trabalho na promoção dos exames ocupacionais já que este tem o conhecimento necessidade para atuar na cavidade bucal do trabalhador, 
sendo que este "deve atuar no reconhecimento e, consequentemente, na prevenção das doenças profissionais que possam ser diagnosticadas através do exame da cavidade bucal sendo a saúde ocupacional um ramo de Medicina Preventiva”(...). (SILVA e MEDEIROS, 2013, p. 105)

Todos os agentes transformadores da realidade da saúde devem atuar no cumprimento do comando constitucional de proteção do trabalhador, com relação a sua saúde e aos riscos que a ele são aplicados, não devendo o odontólogo ser excluído desta realidade, já que este profissional é responsável por pensar a saúde bucal do trabalhador, a partir de lesões bucais passíveis de acometimento pelo trabalho, até a epidemiologia e a patologia desses problemas (ARAÚJO e GONINI JUNIOR, 1999), tudo como meio de empreender a análise dos impactos de cada tipo de trabalho à qualidade de vida do trabalhador. (SILVA e MEDEIROS, 2013)

Portanto, é necessária para o cumprimento do comando constitucional de proteção à saúde do trabalhador, necessário que a norma trabalhista descreva que o trabalhador deve passar por exames ocupacionais odontológicos, como meio deste profissional orientar e informar sobre os riscos do trabalho, buscar a prevenção e a evitar acidentes e doenças profissionais, de forma que o empregador e o empregado tenham o conhecimento necessários para implementação de ações que evitem sinistros e doenças bucais.

\section{CONSIDERAÇÕES FINAIS}

Atualmente, a necessidade da presença do cirurgião-dentista especialista em Odontologia do Trabalho no ambiente laboral é de extrema importância, visto que o mesmo pode influenciar de forma positiva sobre a saúde dos trabalhadores, seja pela identificação de riscos potenciais, seja pela necessidade de educar para a saúde, transformando os trabalhadores em promotores da saúde na empresa. A função do odontólogo do trabalho é promover, prevenir e preservar a saúde bucal do trabalhador pois muitos sofrem acidentes, afecções ou doenças adquiridas na boca durante o exercício profissional.

Como a Odontologia do Trabalho atua na identificação de alterações na boca, controla e orienta o trabalhador a procurar o tratamento no SUS, empresas conveniadas ou qualquer outro meio à escolha e possibilidade do cidadão.

Assim, para que a Odontologia do Trabalho possa continuar a ser um meio de transformação social pela sua atuação, seja ela de forma curativa em processos agudos de dor, seja pela prevenção e promoção da saúde bucal e geral, dentro das empresas, é necessário que o Projeto de Lei seja convertido em lei ordinária pelo Congresso Nacional e depois 
devidamente sancionado pela Presidência da República, alterando a CLT nos dispositivos anteriormente descritos, permitindo assim a inserção do odontólogo nos Programas de Saúde Ocupacional e que este promova os exames ocupacionais nas mesmas condições, formas e momentos da relação laboral que os exames médicos.

\section{REFERÊNCIAS BIBLIOGRÁFICAS}

ABOT. Associação Brasileira de Odontologia do Trabalho. [Internet] Disponível em: http://www.abot.org.br/.Acessado em 28/08/2016.

ARAÚJO, M.E.; GONINI JUNIOR, A. Saúde Bucal do Trabalhador: Os exames admissional e periódico como um sistema de informação em saúde. Odontologia e Sociedade, V. 1, N. 1-2, p. 15-18, São Paulo, 1999.

BRASIL, Consolidação das Leis do Trabalho, Decreto-Lei 5.452, 1º de maio 1943.

BURKET, L. W. Oral medicine: diagnosisandtreatment. Philadelphia, Lippin - cott, 1952.

CONSELHO FEDERAL DE ODONTOLOGIA. Resolução CFO 22/2001 de 27/12/2001 Art. 30. Disponível em: http://www.cfo.org.br. Acessado 28/05/2016.

COSTA, M.T. Odontologia do Trabalho: Uma Perspectiva de Integração aos Sistemas de Gestão da Saúde e Segurança no Trabalho. IV Congresso Nacional de Excelência em Gestão. Niterói, RJ. 2008

CUNHA, L.S. Saúde Bucal do Trabalhador e a Assistência Odontológica nas empresas. Dissertação (Mestrado em Saúde Coletiva). Faculdade de Odontologia de Bauru, Universidade de São Paulo. Bauru, 2005.

GIL, A.C. Como elaborar projetos de pesquisa. Editora Atlas, 5ª Edição, São Paulo, 2008.

HIROISHI, W.K., ROSETTI, E., ORENHA, E.S, NARESSI, S.C.M. Odontologia do Trabalho: um novo olhar sobre a saúde bucal do trabalhador. Braz. Dent. Sci., V.14, n. 3-4, p. 66-76, São Paulo, 2011.

HOBSBAWN, E. A era dos extremos: o breve século XX - 1914-1991. São Paulo: SCHZWARCZ, 1995. 
LAKATOS, E.M., MARCONI, M. A. Fundamentos da Metodologia Científica. Ed. Atlas, $5^{a}$ Edição, São Paulo, 2003.

MAZZILI, L.E.N. Odontologia do Trabalho. Ed Santos. 2003; p.66-67 - 104-114.

MEDEIROS, U. Fundamentos de Odontologia do Trabalho. São Paulo; Santos; 2011: 1-47, 113-75.

MENDES, R. Medicina do trabalho: doenças profissionais. São Paulo: Sarvier, 1980.

MENDES, R., DIAS. E.C. Da medicina do trabalho à saúde do trabalhador. Revista de Saúde Pública, São Paulo, v. 25, n. 5, p. 341-349, 1991.

MORETTI, S. Qualidade de vida no trabalho x auto-realização humana. Instituto Catarinense de PósGraduação, Florianópolis. 2005. Disponível em: http://www.posuniasselvi.com.br/artigos/rev0312.pdf. Acessado em 02/09/2016.

NOGUEIRA, D.P. Odontologia e Saúde Ocupacional. Rev. Saúde Pública, v.6, n.2, p.211-23, Jun. 1972.

OLIVAL, A. R. B., CHARONE, S., GROISMAN, S. A importância do exame odontológico periódico ocupacional: uma proposta de prontuário odontológico. Revista de Odontologia da Universidade Cidade de São Paulo, 2008, v. 20, jan-abr, p. 37-45.

OLIVEIRA SILVA, José Antônio Ribeiro de. A saúde do Trabalhador como um Direito Humano. Revista do Tribunal Regional do Trabalho da $15^{a}$ Região, n. 31, 2007, p. 109-137

PIZZATO, E. , GARBIN, C. A. S. Odontologia do trabalho: implantação da atenção em saúde bucal do trabalhador. Odontologia ClínicalCientífica. 2006, v. 5, nº 2, 99-102.

PROJETO DE LEI 422/2007. Deputado Flaviano Melo/AC. Disponível em: http//www.camara.gov.br/proposiçõesweb/fichadetramitacao/idproposicao=344690. Acessado em 02/09/2016.

RODRIGUES, C.K., DITTERICH, R.G., HEBLING, E. Aspectos éticos e legais da Odontologia do Trabalho. Rev. Inst. Cienc. Saúde, V. 25, N. 4, p.449-53, São Paulo, 2007. 
SÁ, A.C.M.C. A importância dos exames periódicos bucais na saúde do trabalhador. Monografia. 2008. Disponível em: http://www.fundacentro.gov.br/dominios/ctn/anexos/

AcervoDigital/monog.ImportanciaExamesPer.Bucais.pdf. Acessado em 2/09/2016.

SANTOS, A. S. C., MEDEIROS, U. V. Integração entre Medicina, Enfermagem e Odontologia do Trabalho: uma conquista para a população. Rev. Bras. Odontol. V.69, n.1, p. 111-5, Rio de Janeiro, RJ. Jan/Jun. 2012.

SANTOS, M. R. O impacto do absenteísmo odontológico na produtividade laboral. [monografia de especialização]. Campinas: S. L. Mandic; 2007. Disponível em: http://cloralmed.com.br/files/monografia_dr_marcos_odontrab.pdf.Acessado em 2/09/2016.

SILVA, A. M. T. B.; MEDEIROS, U. V. O papel da Odontologia do Trabalho na saúde do trabalhador. Rev. bras. odontol., Rio de Janeiro, v. 70, n. 2, p. 104-8, jul./dez. 2013.

SILVA, M. S., COSTA, S. S., MACEDO, I. A. B. Importância da inserção do cirurgião-dentista nas políticas públicas de saúde do trabalhador. Interfachs 2010. Disponível em http://www.interfacehs.sp.senac.br/indes.php/ITF/article/viewfile/72/78. Acessado em 2/09/2016.

TAMBELLINI, A.T. et al. Occupationalandenviromentalhealth in South America: theresultofrapidchanges in social andeconomicconditions. IN: ANN. 24 thInternationalCongressonOccupational Health. Nice, ICOH, 1993.

TANNOUS, R. A., SILVA, U. A. Revisão de literatura: Odontologia do trabalho: Aplicabilidade e importância na saúde bucal do trabalhador. UFES Rev. Odontol., V.9, N.3, p. 43-48, Vitória, Set/Dez 2007. 